\title{
Cdc42 is highly expressed in colorectal adenocarcinoma and downregulates ID4 through an epigenetic mechanism
}

\author{
TERESA GÓMEZ DEL PULGAR ${ }^{1,2^{*}}$, FÁTIMA VALDÉS-MORA ${ }^{1,2^{*}}$, EVA BANDRÉS ${ }^{3}$, ROSA PÉREZ-PALACIOS ${ }^{1,2}$, \\ CAROLINA ESPINA ${ }^{1,2}$, PALOMA CEJAS ${ }^{2,4}$, MIGUEL ANGEL GARCÍA-CABEZAS ${ }^{2,5}$, \\ MANUEL NISTAL ${ }^{2,5}$, ENRIQUE CASADO ${ }^{2,4}$, MANUEL GONZÁLEZ-BARÓN ${ }^{2,4}$, \\ JESÚS GARCÍA-FONCILLAS ${ }^{3}$ and JUAN CARLOS LACAL ${ }^{1,2}$ \\ ${ }^{1}$ Centro Nacional de Biotecnología, ${ }^{2}$ Translational Oncology Unit CSIC-UAM-La Paz, Madrid; \\ ${ }^{3}$ Center for Applied Medical Research, University of Navarra, Pamplona; \\ Departments of ${ }^{4}$ Medical Oncology and ${ }^{5}$ Pathology, La Paz University Hospital, Madrid, Spain
}

Received February 7, 2008; Accepted March 27, 2008

\begin{abstract}
Cdc42, a member of Rho GTPases family, is involved in the regulation of several cellular functions, such as rearrangement of actin cytoskeleton, membrane trafficking, cell-cycle progression, and transcriptional regulation. Aberrant expression or activity of $\mathrm{Cdc} 42$ has been reported in several tumours. Here, the specific role of $\mathrm{Cdc} 42$ in development and progression of colorectal cancer was analyzed through microarrays technology. A comparative analysis of Cdc42 overexpressing cells versus cells with decreased Cdc42 levels through siRNA revealed that $\mathrm{Cdc} 42$ overexpression downregulated the potential tumour suppressor gene ID4. Results were validated by quantitative RT-PCR and the methylation status of the specific promoter, analyzed. Methylation-specific PCR and bisulfite sequencing PCR analysis revealed that Cdc42 induced the methylation of the $\mathrm{CpG}$ island of the ID4 promoter. Colorectal adenocarcinoma samples were compared with the corresponding adjacent normal tissue of the same patient in order to determine specific gene expression levels. The downregulation of ID4 by Cdc42 was also found of relevance in colorectal adenocarcinoma biopsies. Cdc42 was found to be overexpressed with high incidence $(60 \%)$ in colorectal cancer samples, and this expression was associated with silencing of ID4 with statistical significance $(\mathrm{p}<0.05)$. $\mathrm{Cdc} 42$ may have a role in the development of colon cancer. Furthermore, inhibition of Cdc42 activity may have a direct impact in the management of colorectal cancer.
\end{abstract}

Correspondence to: Professor Juan Carlos Lacal, Centro Nacional de Biotecnología, C/ Darwin 3, Campus de Cantoblanco, Madrid, Spain

E-mail: jclacal@cnb.uam.es

${ }^{*}$ Contributed equally

Key words: Cdc42, ID4, colorectal adenocarcinoma, DNA methylation

\section{Introduction}

The family of small Rho GTPases acts as molecular switches that control key signaling and structural aspects of the cell in response to diverse extracellular stimuli. As a consequence, Rho proteins deregulation results in an active role in human tumourigenesis. Aberrant expression or activity of different members of the Rho family has been detected in many types of human tumours leading to great interest in their cellular effects (1). One of the members, Cdc42, is ubiquitously expressed. It exists in an active GTP-bound, and an inactive GDP-bound form. Signaling by integrins, growth factors, cytokine receptors, and cadherins can activate Cdc42. In its active form, Cdc42 can interact with different effector molecules which, in turn, regulate actin cytoskeleton, microtubule network, cell polarity, proliferation, apoptosis, endocytosis, and secretion (2).

The involvement of Cdc42 in the carcinogenic process is highly associated to aberrant expression and activity of the protein. Indeed, Western blot analysis has revealed that the $\mathrm{Cdc} 42$ protein is overexpressed in breast tumour samples as compared to normal tissues from the same patient $(3,4)$. The view that $\mathrm{Cdc} 42$ is involved in human breast carcinogenesis was also supported in a model of breast carcinoma in rodents where the expression of a dominant inhibitory mutant of Cdc42 reduced the number of focal contacts, inhibited colony formation in soft agar and affected cell growth in vivo. This inactive form reduced intravasation into the peripheral blood, and lung metastasis (5). As well, expression of Cdc42 was found significantly higher in tumour than in normal counterparts from patients with testicular cancer and associated with progression of this type of cancer (6). Moreover, immunohistochemical analysis has revealed that head and neck squamous cell carcinomas overexpress $\mathrm{Cdc} 42$ when compared to the corresponding normal tissue (7).

Not only an increase in protein level is involved in tumourigenesis but also activation of $\mathrm{Cdc} 42$ by surface antigens is implicated in melanoma cell growth and invasion signals to promote cell-spreading (8). In keeping with this, autotoxin promotes invasiveness and angiogenesis through $\mathrm{Cdc} 42$ in 
melanoma (9). Also the involvement of Cdc42 in the control of gene transcription has been recently proposed as a mechanism for its participation in tumour progression (10).

The specific role of $\mathrm{Cdc} 42$ in the development and progression of colorectal cancer has not been yet investigated. In order to analyze Cdc42 transcriptional targets potentially involved in the development of colorectal cancer, stable transfectants of wild-type Cdc42 (Cdc42wt) and Cdc42 siRNA (Cdc42i) were generated in the human colorectal cancer cell line SW620, and a microarray comparative analysis performed. Downregulation of ID4 was observed, a gene previously described as a tumour suppressor in several types of tumours (11-14). Next, the mechanism for ID4 regulation by $\mathrm{Cdc} 42$ was investigated, and the expression levels of Cdc42 in colorectal cancer samples correlated with those of ID4. The results suggest a potential role of Cdc42 in colorectal tumour development.

\section{Materials and methods}

Cell culture. The human colorectal adenocarcinoma cancer cell line SW620 and human CCD18Co normal colon cells were from ATCC (American Type Culture Collection, Manassas, VA). Cells were cultured under standard conditions in DMEM supplemented with $10 \%$ fetal bovine serum (Life Technologies, Grand Island, NY), $2 \mathrm{mM}$ glutamine and $100 \mathrm{U} / \mathrm{ml}$ of penicillin-streptomycin.

Stable transfectants. siRNA against human Cdc42 was designed according to the criteria set out by Agami and coworkers (15). DNA template oligonucleotide (64-nt) was engineered to produce 19-nt sequence derived from the target transcript flanked with AA at the 5' and TT at the 3', and comprising more than $30 \%$ GC content. Candidate sequence was submitted to a BLAST search against the human genome sequence to ensure that only one gene of the human genome was targeted. The oligonucleotide pair was designed to produce restriction site overhangs upon annealing (BglII at the 5 '-end and HindIII at the 3'-end) for cloning into vector pSUPER-neo (15). Sense primer: 5'-GATCCCCCTATGCA GTCACAGT TATGTTCAAGAGACATAACTGTGACTGCATAGTTT TTGGAAA-3' . Antisense primer: 5'-AGCTTTTCCAAAA ACTATGCAGTCACAGTTATGTCTCTTGAACATAACT GTGACTGCATAGGGG-3'. The underlined characters indicate the mRNA target sequences and the bold characters refer to the 9-bp hairpin loop and restriction site overhangs.

Construction of pCDNA3B-neo directing expression of wild-type $\mathrm{Cdc} 42$ protein and conferring neomycin-resistance was previously described (16). For stable transfection, SW620 cells were plated in 6-well dished at 60-70\% confluence. Transfections were performed with Lipofectamine Plus Reagent from Life Technologies as directed by the manufacturer. The amount of plasmidic DNA was kept constant at $5 \mu \mathrm{g}$ per dish with the corresponding empty vector. Following transfection, cells were cultured for $24 \mathrm{~h}$ in fresh medium prior to selection in medium containing $2.5 \mathrm{mg} / \mathrm{ml}$ neomycin (Sigma Chemical Co.) for 12 days.

Patient tissues. A total of 57 colorectal adenocarcinomas were obtained from treatment naïve patients ( 28 men and 15 women; age range 48-86 years) who underwent surgery at La Paz University Hospital of Madrid, between 2003 and 2006. All samples were collected at resection time and immediately frozen. The ethics committee of the La Paz University Hospital of Madrid approved this study. Clinical and pathological variables were determined following wellestablished criteria and summarized in Table I. Local staging was performed according to AJCC. The histological grade of tumours was also determined as follows: grade I as well differentiated, grade II as moderately differentiated, and grade III as poorly differentiated.

Lysis of human tissues. Samples were homogenized and lysed in ice-cold buffer containing $1.5 \mathrm{mM} \mathrm{MgCl}_{2}, 0.2 \mathrm{mM}$ EDTA, $0.3 \mathrm{M} \mathrm{NaCl}, 25 \mathrm{mM}$ HEPES pH 7.5, $20 \mathrm{mM}$ ß-glycerophosphate and $0.1 \%$ Triton $\mathrm{X}-100$ supplemented with phosphatase/protease inhibitors and benzonase. Nuclei and detergent-insoluble material were removed by centrifugation at $14,000 \mathrm{rpm}$ for $20 \mathrm{~min}$ at $4^{\circ} \mathrm{C}$. Protein concentration was determined with Bradford assay (Bio-Rad, Hercules, CA).

Western blot analysis. Lysates containing approximately $20 \mu \mathrm{g}$ of total cellular protein were analyzed by Western blotting after $15 \%$ SDS-polyacrylamide gel electrophoresis using specific monoclonal antibodies for Cdc42 (BD Transduction Laboratories), tubulin (Sigma-Aldrich) and GAPDH (Chemicon International Inc., Temecula, CA, USA). Tubulin or GAPDH expression was used as loading control. Anti-mouse IgGs (Santa Cruz Biotechnology, Heidelberg, Germany) coupled to horseradish peroxidase were used as a secondary antibody for visualization with ECL Western blotting detection system (Amersham Biosciences). The membranes were scanned and then densitometrically analyzed with ImageJ software (Rasband, W.S., Research Services Branch, National Institute of Mental Health, Bethesda, MD, USA, http://rsb.info.nih.gov/ij/). For quantification of the protein, amount of $\mathrm{Cdc} 42$ in stable cells was expressed relative to amount in parental cell line that was set to 1.0 , and in tumours, expression of $\mathrm{Cdc} 42$ was shown relative to the corresponding normal tissue; the latter was set to 1.0.

Real-time RT-PCR. The differential expression of ID4 gene was quantified by real-time reverse transcriptase PCR. Total RNA was prepared from the cell lines using the RNeasy Mini kit (Qiagen, Inc.) and from clinical samples with TRIzol ${ }^{\circledR}$ Reagent (Invitrogen). Total RNA could be obtained in 55 of the 57 clinical cases. For cDNA preparation, $1 \mu \mathrm{g}$ of total RNA was retro transcribed by High-Capacity cDNA Archive Kit (Applied Biosystems, Foster City, CA, USA) at $37^{\circ} \mathrm{C}$ for $2 \mathrm{~h}$. Then, each cDNA sample was analyzed in triplicate using the ABI PRISM 770 Sequence Detector (Applied Biosystems). 18S ribosomal mRNA was amplified along with target gene mRNA for an internal control.

Primers and probes used for amplification were purchased from Applied Biosystems as TaqMan ${ }^{\circledR}$ Gene Expression assays (ID4 Assay ID: Hs00155465_m1; 18S ribosomal RNA assay ID: Hs99999901_s1). Relative quantitation of gene expression was calculated with the $2^{-\Delta \Delta C t}$ method [Applied Biosystems User Bulletin $\mathrm{N}^{\circ} 2(\mathrm{P} / \mathrm{N}$ 4303859)]. The data are presented as the quantity of ID4 gene in each tumoural sample, normalized 
Table I. Clinical and pathological information of the colorectal adenocarcinoma patients analyzed in this study $(n=57)$.

\begin{tabular}{|c|c|c|c|}
\hline & Total & $\begin{array}{l}\text { Low Cdc42 } \\
\text { expression }\end{array}$ & $\begin{array}{c}\text { High Cdc42 } \\
\text { expression }\end{array}$ \\
\hline No. of patients & 57 & 23 & 34 \\
\hline $\begin{array}{l}\text { Median age, } \\
\text { years (range) }\end{array}$ & $71(48-86)$ & $71(54-86)$ & $69.5(48-86)$ \\
\hline \multicolumn{4}{|l|}{ Gender } \\
\hline Male & 39 & 18 & 21 \\
\hline Female & 18 & 5 & 13 \\
\hline \multicolumn{4}{|l|}{ Primary tumor $(\mathrm{pT})$} \\
\hline pT2 & 5 & 2 & 3 \\
\hline pT3 & 43 & 18 & 25 \\
\hline pT4 & 9 & 3 & 6 \\
\hline \multicolumn{4}{|l|}{$\begin{array}{l}\text { Regional lymph } \\
\text { nodes }(\mathrm{pN})\end{array}$} \\
\hline pNO & 31 & 11 & 20 \\
\hline $\mathrm{pN} 1$ & 16 & 10 & 6 \\
\hline $\mathrm{pN} 2$ & 8 & 2 & 6 \\
\hline $\mathrm{pNx}$ & 2 & & \\
\hline \multicolumn{4}{|l|}{ Histological grade } \\
\hline Well differentiated & 2 & 1 & 1 \\
\hline $\begin{array}{l}\text { Moderately } \\
\text { differentiated }\end{array}$ & 41 & 19 & 22 \\
\hline $\begin{array}{l}\text { Poorly } \\
\text { differentiated }\end{array}$ & 14 & 3 & 11 \\
\hline
\end{tabular}

to the endogenous reference gene and relative to its corresponding matched normal tissue.

Detection of hypermethylation status of ID4 promoter region. DNA extraction and bisulfite modification. Genomic DNA from cell lines and clinical samples was isolated using the DNeasy Tissue Kit (Qiagen, Inc.). DNA ( $1 \mu \mathrm{g})$ was modified by bisulfite conversion with the CpGenome ${ }^{\mathrm{TM}}$ DNA Modification Kit (Chemicon International) according to the manufacturer's instructions. Following sodium bisulfite modification DNA was applied for methylation specific PCR and bisulfite sequencing. For methylation-specific assays the cell lines HEK293T and CCD18Co were used as negative controls, since both express ID4 gene, and human male genomic DNA universally methylated for all genes (Chemicon International) as a positive control.

Methylation specific PCR (MSP). Methylation status of ID4 promoter region was analyzed by methylation-specific PCR (MSP). The methylation and unmethylation-specific primer sets are shown in Table II. PCR reactions were carried out in a total volume of $20 \mu \mathrm{l}$ containing $2 \mu \mathrm{l}$ of bisulfite modified DNA. One $\mathrm{mM} \mathrm{Mg}^{2+}$ for ID4 methylation-specific primer

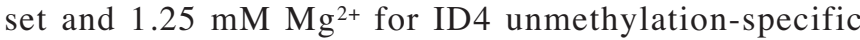
primer set was used. In total, 35 amplification cycles for methylation-specific primer set and 40 amplification cycles for unmethylation-specific primer set were performed with an initial denaturation at $95^{\circ} \mathrm{C}$ for $12 \mathrm{~min}$ and a final extension at $72^{\circ} \mathrm{C}$ followed for $10 \mathrm{~min}$. The annealing temperature for the specific primer set is shown in Table II.

Bisulfite sequencing PCR (BSP). The $\mathrm{CpG}$ island methylation status was also determined by sequencing of PCR products PCR amplification was done in a $50 \mu \mathrm{l}$ volume with $2 \mu \mathrm{l}$ template for 40 cycles of $30 \mathrm{sec}$ at $95^{\circ} \mathrm{C}, 30 \mathrm{sec}$ at $60^{\circ} \mathrm{C}$, and $1 \mathrm{~min}$ at $72^{\circ} \mathrm{C}$, followed by a 10 -min final extension at $72^{\circ} \mathrm{C}$ with the use of $2.5 \mathrm{mM}$ of $\mathrm{Mg}^{2+}$.

Amplification products obtained in PCR reactions were subcloned into $\mathrm{pCR}^{\circledR}{ }^{\circledR}$ 4-TOPO ${ }^{\circledR}$ plasmid using TOPO TA Cloning ${ }^{\circledR}$ Kit for Sequencing (Invitrogen Life Technologies, Paisley, UK) and transformed into Escherichia coli according to the manufacturer's recommendations. Colonies with recombinant plasmids containing the described $\mathrm{PCR}$ products were screened by digestion with EcoRI (Amersham Biosciences, Buckinghamshire, UK). Candidate plasmid clones were sequenced with ABI-PRISM ${ }^{\mathrm{TM}}$ d-Rhodamine Terminator Cycle Sequencing Kit (Applied Biosystems) in an ABI PRISM 377 DNA Sequencer (Applied Biosystems) using T7 and T3 universal forward and reverse primers.

Table II. Primer sequences and annealing temperatures used in methylation analysis of promoter region of ID4 through MSP and BSP assays.

\begin{tabular}{|c|c|c|c|c|c|c|}
\hline Gene & Assay & & Sequences & $\begin{array}{l}\text { Product } \\
\text { size (bp) }\end{array}$ & $\begin{array}{c}\text { Temperature } \\
\left({ }^{\circ} \mathrm{C}\right)\end{array}$ & Ref. \\
\hline \multirow[t]{4}{*}{ ID4 } & MSP & M1 & 5'-TTT TAT AAA TAT AGT TGC GCG GC-3' & 132 & 55 & $(11)$ \\
\hline & & M2 & 5'-GAA ACT CCG ACT AAA CCC GAT-3' & & & \\
\hline & & $\mathrm{U} 1$ & 5'-TTT TAT AAA TAT AGT TGT GTG GTG G-3' & 135 & 58 & \\
\hline & & $\mathrm{U} 2$ & 5'-TCA AAA CTC CAA CTA AAC CCA AT-3' & & & \\
\hline \multirow[t]{2}{*}{ ID4 } & $\mathrm{BSP}$ & $\mathrm{F}$ & 5'-TTT TAT TCG GGT AGT CGG ATT TTT CGT TTT TTA GTA T-3' & 317 & 60 & $(11)$ \\
\hline & & $\mathrm{R}$ & 5'-CCC ACC CGA ATA TCC TAA TCA CTC CCT TC-3' & & & \\
\hline
\end{tabular}


Statistical analysis. The relation between Cdc42 protein expression and the different clinicopathological parameters was assessed by means of the Mann-Whitney test. The association between $\mathrm{Cdc} 42$ and ID4 expression in colon cancer samples was assessed with Fisher's exact test. The statistical analysis was performed using SPSS software, version 13 (Chicago, IL) and statistical significance was defined as $\mathrm{p}<0.05$.

\section{Results}

Overexpression of $\mathrm{Cdc} 42$ significantly reduces message levels of the putative tumour suppressor gene ID4 in SW620 cells. Stable transfectants through overexpression of wild-type $\mathrm{Cdc} 42$ (Cdc42wt) and reduction of $\mathrm{Cdc} 42$ levels by specific Cdc42 siRNA (Cdc42i) were generated in the human colorectal cancer cell line SW620 to investigate gene expression changes attributed to $\mathrm{Cdc} 42$ function. Based on Western blot analysis, two clones for each modification were selected for further studies (Fig. 1A). Stable transfectants overexpressing Cdc42 (Fig. 1A, wt1, wt2), and siRNA transfectants with reduced Cdc42 expression (Fig. 1A, i1, i2) were selected.

A comparative microarray analysis (Gómez del Pulgar et al, unpublished data) of the generated cell lines vs. the parental cell line showed that interference of $\mathrm{Cdc} 42$ expression induced the expression of ID4, previously described as a tumour suppressor in some human tumours (11-14). Their corresponding mRNA levels were validated in stable transfectants by real-time RT-PCR. Cells with a drastic reduction of Cdc42 levels (i1, i2), have increased mRNA levels for ID4 (Fig. 1B). In contrast, stable cells expressing Cdc42 wildtype have reduced mRNA levels for ID4 (Fig. 1B).

Cdc42 silences ID4 gene through its promoter hypermethylation. Since the mechanism for ID4 expression has been linked to epigenetic regulation (11-14,17), the methylation status of the promoter region of ID4 was examined. To determine promoter hypermethylation, a methylation specific PCR (MSP) method was used (18). Primers are designed to distinguish methylated from unmethylated DNA (Table II) in bisulfite-modified DNA, taking advantage of the sequence differences resulting from bisulfite modification. Bisulfite converts unmethylated cytosine residues to uracil, but methylated cytosines remain unaffected. PCR amplifies uracil as thymine while methylated cytosines amplify as cytosines. Two controls are required for this PCR: DNA from cell lines which express the gene served as control for unmethylated (U) pattern, and CpGenome Universal Methylated DNA as positive control for methylated (M) DNA.

The human normal colon cell line CCD18Co and the human embryonic kidney cell line HEK293T, which express this gene (data not shown), showed a positive band for unmethylated DNA, whereas the human colorectal cancer cell line SW620 had the hypermethylated promoter for ID4 (Fig. 2A). SW620 cells transfected with siRNA (i1, i2) showed positive bands for both $\mathrm{M}$ and $\mathrm{U}$ patterns, whereas cells transfected with plasmid expressing wild-type Cdc42 (wt1, wt2) gave only a positive band for M pattern. Overexpression of $\mathrm{Cdc} 42$ had no differences with the parental cell line, already methylated. However, Cdc42-depleted

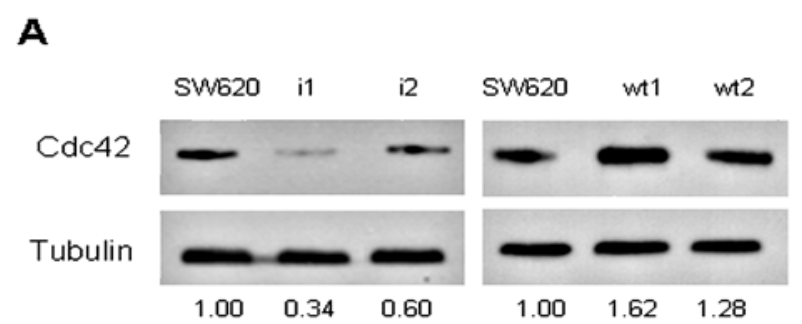

\section{B}

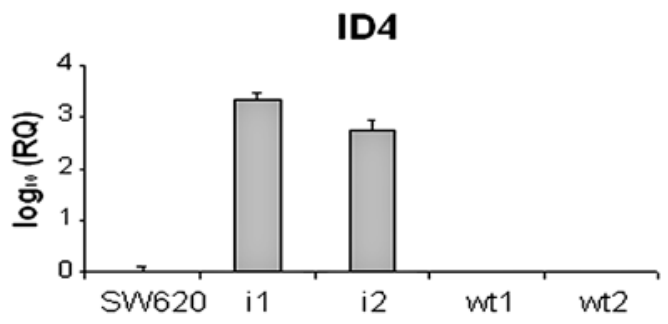

Figure 1. Repression of the tumour suppressor gene ID4 by Cdc42. A, Expression of Cdc42 was analyzed in stable transfected SW620 cells. Total protein $(20 \mu \mathrm{g})$ was separated on $15 \%$ SDS-PAGE and Western blot analysis of $\mathrm{Cdc} 42$ protein expression was performed with anti-Cdc42 monoclonal antibody. Tubulin levels are shown as a loading control. Densitometrical analysis of relative amount of $\mathrm{Cdc} 42$ in each cell line is shown. B, Total RNA from stable transfected cells was subjected to quantitative TaqMan RT-PCR analysis for ID4 mRNA levels. The $2^{--\Delta \Delta C t}$ method was used to compare gene expression data in stable cells with Cdc42 modified levels relative to expression in SW620 parental cell line. The results are shown as $\log _{10}$ of relative quantity (RQ).

cells showed unmethylated DNA, inducing recovery of the expression of ID4 (Fig. 1B).

The methylation status of ID4 was confirmed by sequencing of bisulfite modified genomic DNA (Fig. 2B). In this method, after bisulfite modification, the promoter region of interest is amplified by PCR. The primers for bisulfite sequencing PCR (BSP) of ID4 (Table II) amplify a region with more $\mathrm{CpG}$ sites than MSP and contain the minimal promoter region. Consistent with the methylation-specific PCR results, in SW620 most of the $41 \mathrm{CpG}$ sites examined were methylated. In SW620 cells transfected with siRNA, the $41 \mathrm{CpG}$ sites examined were completely unmethylated, except site 27 (Fig. 2B, Cdc42i), and cells overexpressing Cdc42 were slightly different from the parental cell line SW620, with more CpG sites methylated (Fig. 2B, Cdc42wt), a result consistent with a more efficient activity by overexpression of Cdc42.

Cdc42 is highly overexpressed and associated with silencing of ID4 in colorectal adenocarcinoma. Western blot or immunohistochemical analysis using specific polyclonal antibodies provided evidence that the levels of $\mathrm{Cdc} 42$ are increased in breast, testicular cancer, and head and neck squamous cell carcinoma $(3,4,6,7)$. In order to understand the possible clinical relevance of the above results, protein expression of Cdc42 was studied in tumoural tissues from 57 patients with colorectal adenocarcinoma. Pathological and clinical parameters available of these patients are summarized in Table I. Protein was extracted from tumour tissues and their corresponding normal adjacent tissue from the same 
A

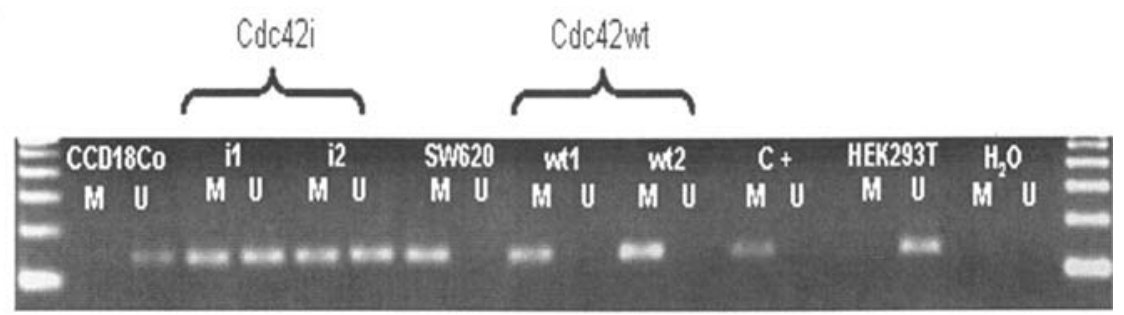

B
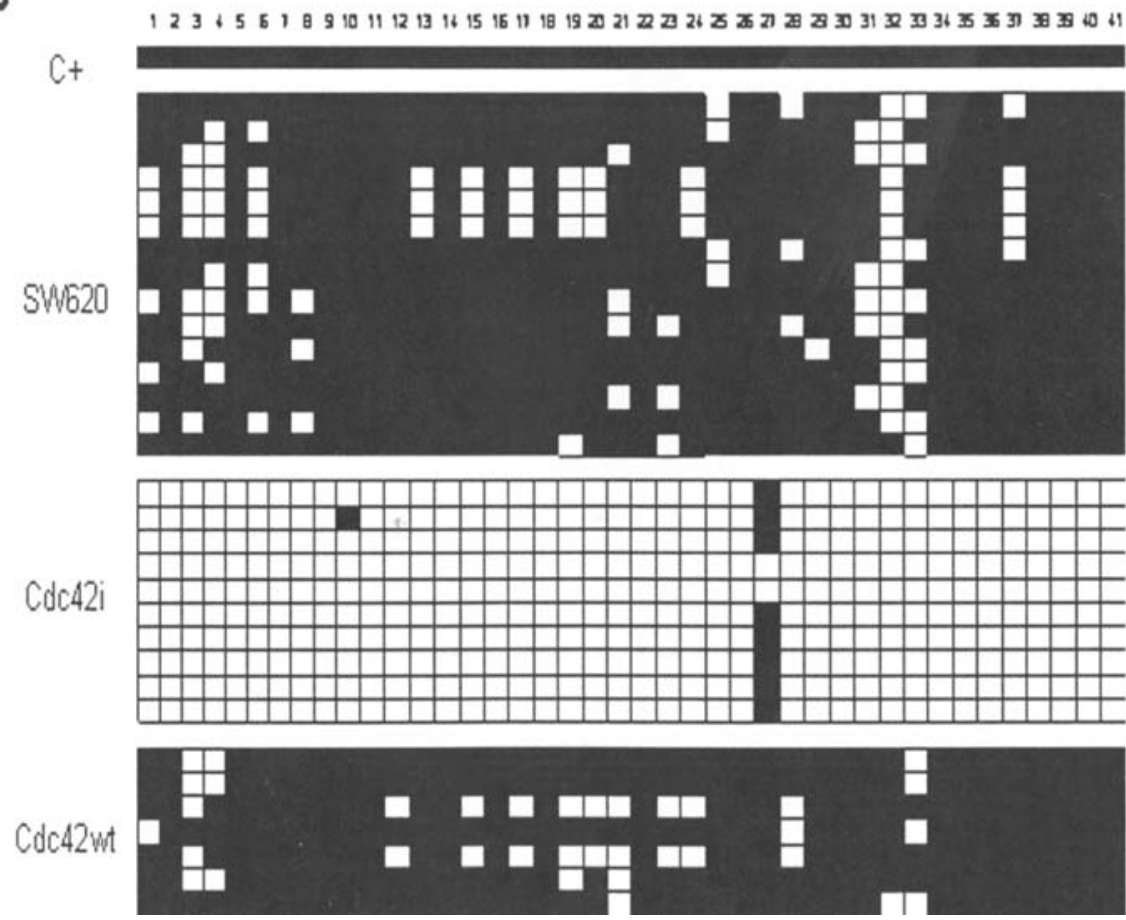

Figure 2. Analysis of methylation status of the promoter region of ID4 in stable transfected SW620 cells. A, Methylation-specific PCR analysis of ID4 gene promoter. DNA extracted from stable transfected cells was modified with sodium bisulfite and amplified by PCR with primer sets designated as unmethylated (U) and methylated (M). The size of the PCR products was as indicated in Table II. The human normal colon cell line CCD18Co and the human embryonic kidney cell line HEK293T, that express the gene, showed a positive band in the reaction with the unmethylated (U) primers, being controls for unmethylated pattern. CpGenome Universal Methylated DNA served as positive control for methylated DNA. B, Bisulfite sequencing analysis of ID4 promoter region. Genomic DNA was modified with sodium bisulfite; ID4 proximal promoter region was amplified by PCR, cloned and sequenced. The degree of methylation on each $\mathrm{CpG}$ dinucleotide was obtained from several individual clones. Methylated $\mathrm{CpG}$ sites are highlighted in black, whereas white boxes indicate unmethylated $\mathrm{CpG}$ site. All 41 CpG sites were fully methylated when sequencing CpGenome Universal Methylated DNA as positive control. Representative results of SW620 cells transfected with siRNA are shown with $C d c 42 i$ and cells overexpressing Cdc42 with $C d c 42 w t$.

individual. The levels of $\mathrm{Cdc} 42$ protein were analyzed by Western blotting with a specific monoclonal antibody. Representative examples of Western blotting results are shown in Fig. 3A. A total of 34 out of the 57 tumours analyzed $(60 \%)$ displayed more than 1.5-fold-increase in the levels of Cdc42 protein (Fig. 3B, mean \pm SEM is $4.76 \pm 0.92$ ). These results indicate that $\mathrm{Cdc} 42$ is actually overexpressed with high incidence in colorectal cancer patients.

The relationship between Cdc42 overexpression and clinical or pathological characteristics of the tumour was also analyzed in order to study the putative relevance of $\mathrm{Cdc} 42$ as a prognostic factor in colorectal cancer. Overexpression of Cdc42 was independent of age or gender of the patient (data not shown) and of the tumour or lymph node invasion
(Fig. 3C). However, there was a significant association with histopathological tumour grade, which represents tumour cell differentiation ( $p=0.026)$ (Fig. 3C). These results indicate that high level expression of Cdc42 might constitute a new prognostic factor in colorectal cancer patients.

Next, the expression level of the gene ID4 was analyzed using quantitative RT-PCR. ID4 expression was found to be lower in colorectal carcinomas than in normal colon tissue for 27 of 55 samples (Fig. 4A), which is in keeping with the proposed tumour suppressor role for this gene (12). MSP analysis of the ID4 promoter region was performed in tissues with downregulation of the gene (Fig. 4B). A statistically significant association between overexpression of $\mathrm{Cdc} 42$ and silencing of ID4 was found in the clinical samples $(\mathrm{p}=0.026)$, 
A
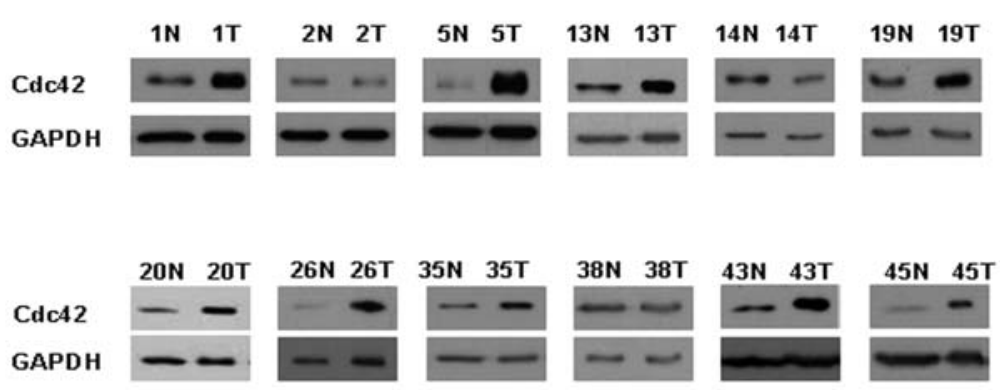

B

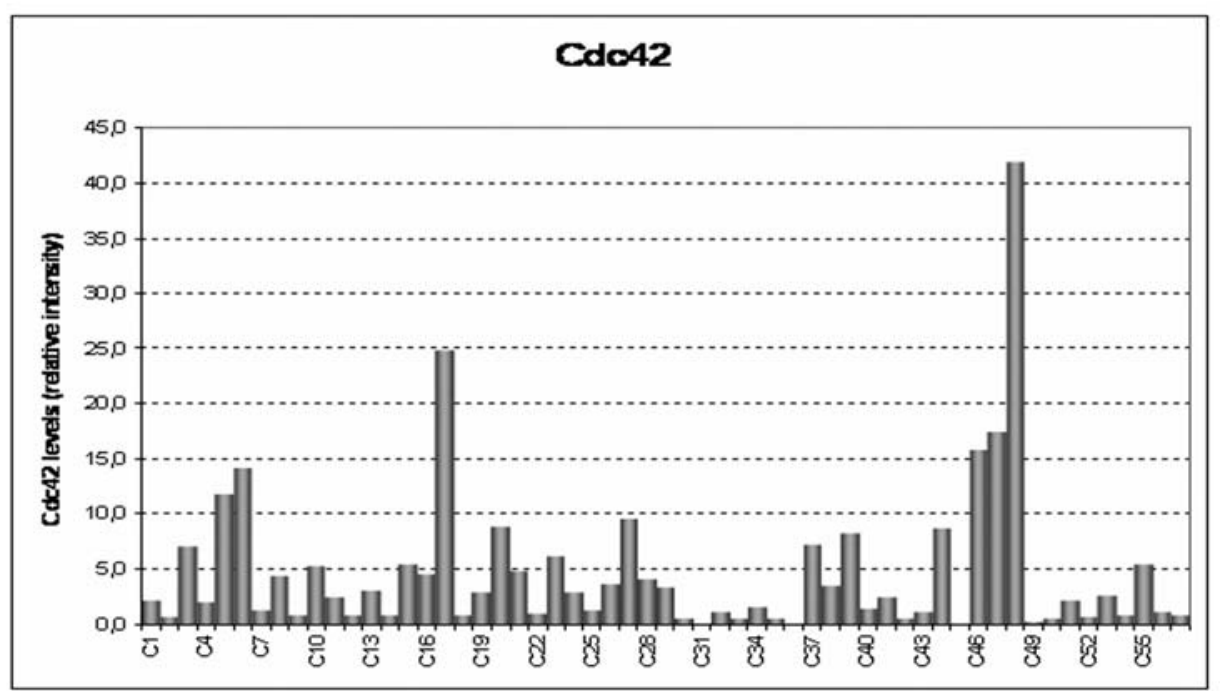

C
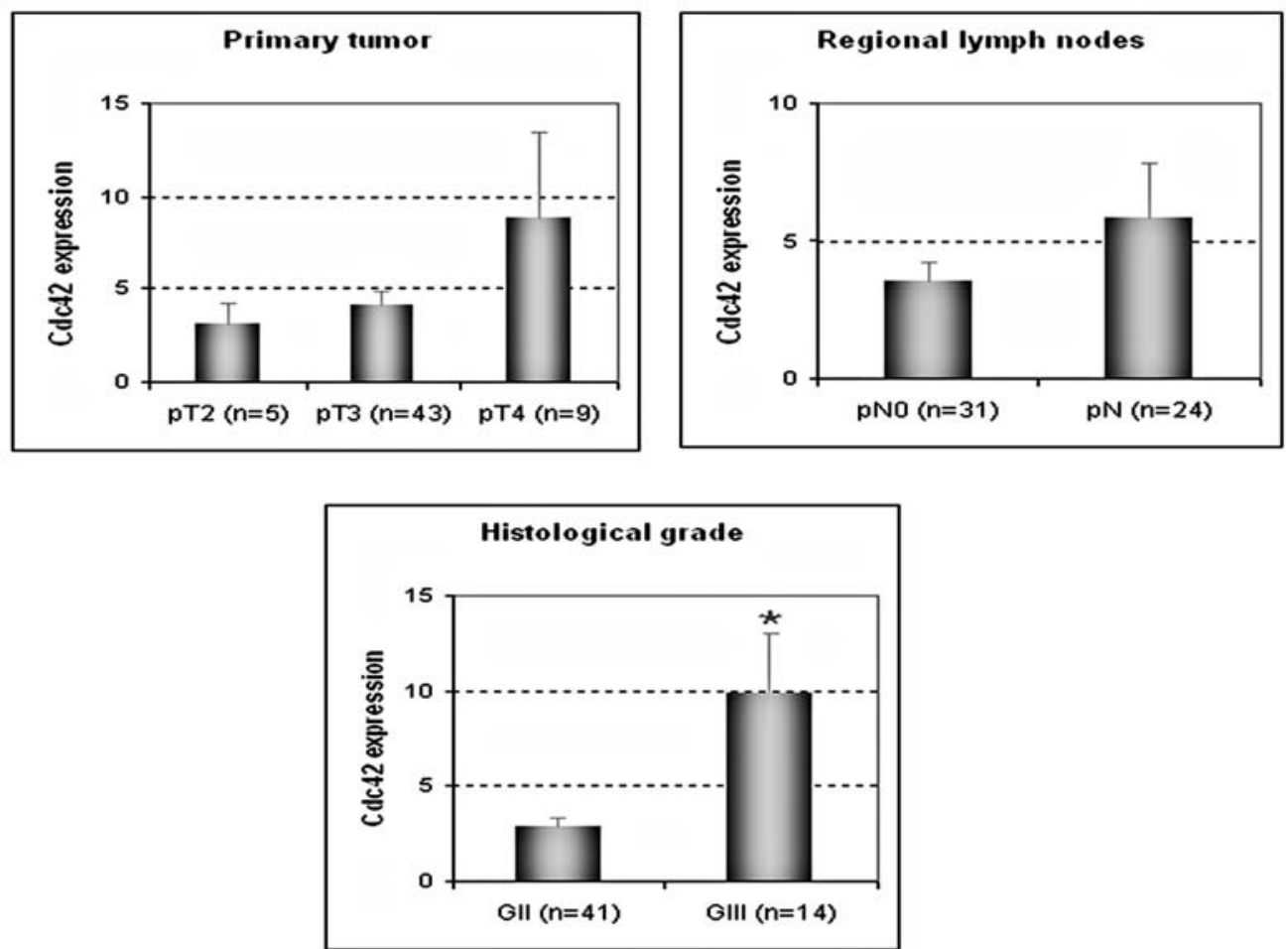

Figure 3. Expression of $\mathrm{Cdc} 42$ in tumoral and normal tissue samples from colon. A, Protein isolated from normal and tumoral tissues (20 $\mu \mathrm{g}$ ) obtained from 57 patients was separated by $15 \%$ SDS-PAGE and subjected to Western blot analysis of Cdc42 levels. Analysis of GAPDH protein was used as loading control. Results are shown for representative cases. B, Densitometrical analysis was performed with ImageJ software. Cdc42 expression was analyzed in each tumoral sample compared to its corresponding normal mucosa tissue, which was set to 1.0. C, The relationship between Cdc42 overexpression and characteristics of the tumour was also analyzed. Mean value of $\mathrm{Cdc} 42$ expression in tumoral samples was significantly associated with histological grade $(\mathrm{p}=0.026$, GIII vs. GII). 
A

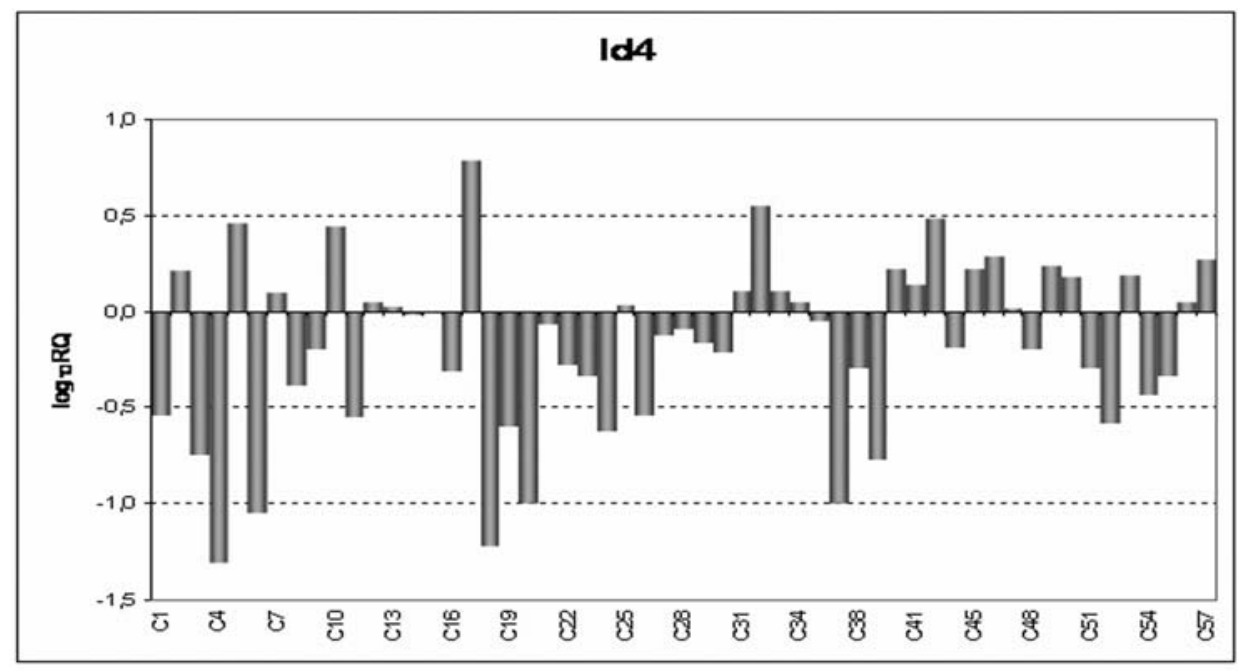

$\mathbf{B}$

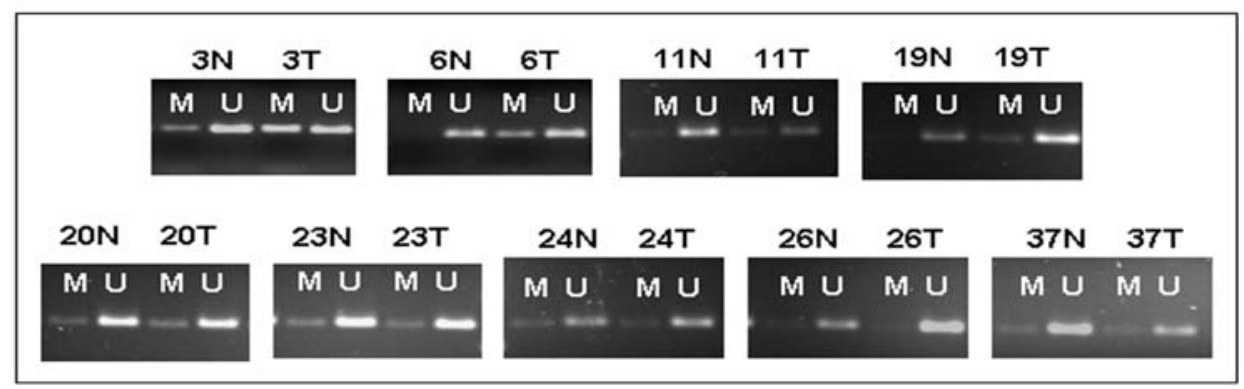

Figure 4. Analysis of ID4 gene expression and promoter methylation status in patients with colorectal adenocarcinoma. A, Expression of ID4 mRNA in colorectal tumours and adjacent normal colon epithelial tissues from the same patient was analyzed by quantitative TaqMan RT-PCR. The $2-4 \mathrm{Ct}$ method was used to compare gene expression data in the different tumoral tissues relative to gene expression in the corresponding normal tissue. Results are shown as logarithm in base 10 of relative quantity (RQ). B, Representative analysis of methylation-specific PCR results for ID4 gene promoter of colorectal tumours and their corresponding normal mucosa samples. Genomic DNA extracted from colorectal samples was modified with sodium bisulfite and amplified by PCR with $\mathrm{M}$ and $\mathrm{U}$ primer sets. The size of the PCR products was as indicated in Table II. Controls for unmethylated and methylated DNA were the same used as described in Fig. 2A (not shown).

since 21 out of the 27 samples with suppression of ID4 matched to $\mathrm{Cdc} 42$ overexpression.

\section{Discussion}

The oncogenic activity of $\mathrm{Cdc} 42$ is related to its involvement in key cellular processes such as control of cell cycle, gene expression, cell migration, invasion and metastasis (1). Aberrant expression or activity of $\mathrm{Cdc} 42$ has been shown previously for breast cancer, testicular tumours, melanoma, and head and neck squamous cell carcinomas $(3,4,6,7)$. These studies barely approach the role of Cdc42, since several GTPases are analyzed together. Here we provide the first evidence of the functional contribution of $\mathrm{Cdc} 42$ to colorectal carcinogenesis. This tumour type is the result of accumulation of genetic changes in key genes, including aberrant activation of oncogenes and inactivation of tumour suppressor genes (19). These genes may be silenced by mutations, chromosomal deletions, transcriptional repression and epigenetic modification through aberrant promoter hypermethylation. Our results show that overexpression of $\mathrm{Cdc} 42$ might contribute to the development of colorectal cancer through inactivation of the tumour suppressor gene ID4.
ID4 is a member of the family of inhibitors of DNAbinding (ID), which inhibits DNA binding of basic helixloop-helix transcription factors. It is suggested that ID4 plays a key role in cell differentiation. The relevance of this gene as tumour suppressor and its epigenetic inactivation has been already proposed in gastric adenocarcinoma (11), colorectal carcinomas (12), breast cancer (13) and leukaemia (14), and might affect tumour differentiation and progression. We demonstrate here that Cdc42 represses ID4 in SW620 through hypermethylation of its promoter region. Among the hypothesis that could explain the mechanism by which $\mathrm{Cdc} 42$ induces epigenetic silencing of ID4, the modulation of the levels of DNMTs was the most plausible. It has been widely described that overexpression of DNMTs is a frequent feature in cancer (20). However, when the levels of these enzymes were analyzed in the generated stable cell lines, no effect on these enzymes was observed (data not shown). Furthermore, DNMT overexpression seems not to be responsible for the aberrant methylation observed in human colorectal tumours (21), since the frequency or extent of $\mathrm{CpG}$ island hypermethylation in individual tumours did not correlate with the expression of any of the DNMTs. It is also conceivable that other factors regulate the activity of the DNA methyltrans- 
ferases, either by interacting with the enzymes themselves or by regulating access to the DNA substrate (20).

This is also the first report on the expression levels of $\mathrm{Cdc} 42$ in colorectal cancer. Our results indicate that $\mathrm{Cdc} 42$ is overexpressed with high incidence $(60 \%)$ in these patients. Only a few markers have been shown to be present in such incidence in colorectal cancer. For instance, K-ras gene mutations are believed to be among the earliest events in colorectal tumourigenesis, present in approximately $70 \%$ of cancers and $40 \%$ of adenomas. Then, Cdc42 could be a new tumoural marker of this type of tumour.

Loss of expression of ID4 in primary cancer samples compared to the corresponding samples of normal colonic mucosa was observed in 27 of the 55 analyzed cases, and of these, 21 overexpressed $\mathrm{Cdc} 42(\mathrm{p}=0.026)$. These results are consistent with $\mathrm{Cdc} 42$ as an inducer of ID4 silencing by an epigenetic mechanism. Further investigation will be required to confirm this interesting and novel observation. Inactivation of expression of ID4 may not be explained only by hypermethylation of its promoter region, an indication of the limitations imposed by genetic variability and tumour heterogeneity. Since MSP can detect a very small percentage of methylated DNA in abundant unmethylated DNA (18), the MSP results for M pattern would be positive if only a small proportion of cells was hypermethylated. This has to be taken into consideration as the normal tissue was obtained from adjacent normal mucosa of cancer samples, and there is the possibility that few cancer cells could be contaminating the normal tissue sample. Another possible explanation is that methylation of ID4 promoter might be related to the early steps in the complex process of malignant transformation. Thus, methylation of $\mathrm{CpG}$ islands may occur early in the process of carcinogenesis, and therefore the methylation could be detected in the apparently normal epithelium (20).

Rho family GTPases are involved at different stages of tumour development (1). In this study, a significant overexpression of $\mathrm{Cdc} 42$ was observed in patients with colorectal adenocarcinoma that is associated with differentiation grade of the tumour $(\mathrm{p}=0.026)$. It is known that Rho proteins are involved in the maintenance of normal epithelial cell polarity, which depends on the structural asymmetry of apical and basolateral plasma membrane domains. Deregulation of Rho activity is involved in the loss of epithelial polarity, important in the epithelial-mesenchymal transition. The significant association of the expression of Cdc42 with the degree of differentiation of the tissue could be due to its role in controlling changes in actin cytoskeleton and in the establishment of cell polarity (22). The prognosis of patients with colorectal cancer is based mainly on clinicopathological staging; also an important biological role has been attributed to tumour grade, as for example, stage II poorly differentiated tumours are considered to require adjuvant chemotherapy $(23,24)$. The degree of differentiation of tumour tissue has generally been considered to reflect the grade of malignancy, as a measure of cancer progression and is the only histological variable that is routinely used for tumour grading. This study supports that $\mathrm{Cdc} 42$ may be considered as a new target in colorectal cancer therapy. The recently discovered small molecule secramine, which inhibits Cdc42 activation in vitro and Cdc42-dependent functions in cells (25), provides a new means to target Cdc42. It would be interesting to further investigate the possible inactivation of $\mathrm{Cdc} 42$ in this type of tumour as a new antitumoural strategy.

\section{Acknowledgements}

This work was supported by Ministerio de Educación y Ciencia (SAF2004-0577 and SAF2005-06195-C02-01), Comunidad de Madrid (S-BIO/0280/2006), Ministerio de Sanidad (RETICC RD06/0020/0016), and by TCD Pharma SL.

\section{References}

1. Gómez del Pulgar T, Benitah SA, Valeron PF, Espina C and Lacal JC: Rho GTPase expression in tumourigenesis: evidence for a significant link. Bioessays 27: 602-613, 2005

2. Bishop AL and Hall A: Rho GTPases and their effector proteins. Biochem J 348: 241-255, 2000.

3. Fritz G, Brachetti C, Bahlmann F, Schmidt M and Kaina B: Rho GTPases in human breast tumours: expression and mutation analyses and correlation with clinical parameters. Br J Cancer 87: 635-644, 2002.

4. Fritz G, Just I and Kaina B: Rho GTPases are over-expressed in human tumors. Int J Cancer 81: 682-687, 1999.

5. Bouzahzah B, Albanese C, Ahmed F, et al: Rho family GTPases regulate mammary epithelium cell growth and metastasis through distinguishable pathways. Mol Med 7: 816-830, 2001.

6. Kamai T, Yamanishi T, Shirataki H, et al: Overexpression of RhoA, Rac1, and Cdc42 GTPases is associated with progression in testicular cancer. Clin Cancer Res 10: 4799-4805, 2004.

7. Abraham MT, Kuriakose MA, Sacks PG, et al: Motility-related proteins as markers for head and neck squamous cell cancer. Laryngoscope 111: 1285-1289, 2001.

8. Eisenmann KM, McCarthy JB, Simpson MA, et al: Melanoma chondroitin sulphate proteoglycan regulates cell spreading through Cdc42, Ack-1 and p130cas. Nat Cell Biol 1: 507-513, 1999 .

9. Jung ID, Lee J, Yun SY, et al: Cdc42 and Rac1 are necessary for autotaxin-induced tumor cell motility in A2058 melanoma cells. FEBS Lett 532: 351-356, 2002.

10. Benitah SA, Valeron PF, van Aelst L, Marshall CJ and Lacal JC: Rho GTPases in human cancer: an unresolved link to upstream and downstream transcriptional regulation. Biochim Biophys Acta 1705: 121-132, 2004

11. Chan AS, Tsui WY, Chen X, et al: Downregulation of ID4 by promoter hypermethylation in gastric adenocarcinoma. Oncogene 22: 6946-6953, 2003

12. Umetani N, Takeuchi H, Fujimoto A, Shinozaki M, Bilchik AJ and Hoon DS: Epigenetic inactivation of ID4 in colorectal carcinomas correlates with poor differentiation and unfavorable prognosis. Clin Cancer Res 10: 7475-7483, 2004.

13. Umetani $\mathrm{N}$, Mori $\mathrm{T}$, Koyanagi $\mathrm{K}$, et al: Aberrant hypermethylation of ID4 gene promoter region increases risk of lymph node metastasis in T1 breast cancer. Oncogene 24: 4721-4727, 2005.

14. Yu L, Liu C, Vandeusen J, et al: Global assessment of promoter methylation in a mouse model of cancer identifies ID4 as a putative tumor-suppressor gene in human leukemia. Nat Genet 37: 265-274, 2005.

15. Brummelkamp TR, Bernards R and Agami R: A system for stable expression of short interfering RNAs in mammalian cells. Science 296: 550-553, 2002.

16. Aznar S, Valeron PF, del Rincon SV, Perez LF, Perona R and Lacal JC: Simultaneous tyrosine and serine phosphorylation of STAT3 transcription factor is involved in Rho A GTPase oncogenic transformation. Mol Biol Cell 12: 3282-3294, 2001.

17. Hagiwara K, Nagai H, Li Y, Ohashi H, Hotta T and Saito H: Frequent DNA methylation but not mutation of the ID4 gene in malignant lymphoma. J Clin Exp Hematop 47: 15-18, 2007.

18. Herman JG, Graff JR, Myohanen S, Nelkin BD and Baylin SB: Methylation-specific PCR: a novel PCR assay for methylation status of CpG islands. Proc Natl Acad Sci USA 93: 9821-9826, 1996. 
19. Fearon ER and Vogelstein B: A genetic model for colorectal tumorigenesis. Cell 61: 759-767, 1990.

20. Jones PA and Baylin SB: The fundamental role of epigenetic events in cancer. Nat Rev Genet 3: 415-428, 2002.

21. Eads CA, Danenberg KD, Kawakami K, Saltz LB, Danenberg PV and Laird PW: CpG island hypermethylation in human colorectal tumors is not associated with DNA methyltransferase overexpression. Cancer Res 59: 2302-2306, 1999.

22. Etienne-Manneville S: Cdc42 - the centre of polarity. J Cell Sci 117: 1291-1300, 2004.
23. Van Cutsem EJD: Colon cancer: ESMO clinical recommendations for diagnosis, adjuvant treatment and follow-up. Ann Oncol 18 (Suppl. 2): ii21-ii22, 2007.

24. Greene FL, Stewart AK and Norton HJ: A new TNM staging strategy for node-positive (stage III) colon cancer: an analysis of 50,042 patients. Ann Surg 236: 416-421, 2002.

25. Pelish HE, Peterson JR, Salvarezza SB, et al: Secramine inhibits $\mathrm{Cdc} 42$-dependent functions in cells and $\mathrm{Cdc} 42$ activation in vitro. Nat Chem Biol 2: 39-46, 2006. 